\title{
Relationship of gold and penicillamine therapy to diffuse interstitial lung disease
}

\author{
D. L. $\operatorname{SCOTT}^{1}$ G. V. H. BRADBY, ${ }^{1}$ T. J. AITMAN, ${ }^{1}$ \\ G. C. ZAPHIROPOULOS, ${ }^{2}$ AND C. F. HAWKINS ${ }^{1}$
}

From the ${ }^{1}$ Rheumatism Research Wing, University of Birmingham, and the ${ }^{2}$ Department of Rheumatology, Coventry and Warwickshire Hospital, Coventry

SUMMARY Seven cases of diffuse interstitial lung disease (DILD) are reported with an unequivocal temporal relationship between the development of the lung disease and treatment with gold (6 cases) and penicillamine ( 1 case). They were characterised clinically by the sudden onset of dyspnoea and crepitations and radiologically by diffuse bilateral pulmonary shadowing. Most showed evidence of hypersensitivity such as eosinophilia, a raised serum IgE level in response to gold, proteinuria, thrombocytopenia, or an immediate postinjection reaction. DILD is a serious complication of treatment with gold and penicillamine that is commoner than generally realised.

Diffuse interstitial lung disease (DILD) may occur in association with rheumatoid arthritis (RA). In one series of 516 patients with RA $1.6 \%$ also had DILD. ${ }^{1}$ In 1976 Geddes and Brostoff ${ }^{2}$ and Winterbauer $e t$ al. ${ }^{3}$ both reported a possible relationship between DILD and gold therapy. Since then a number of reports have described DILD developing during gold therapy. ${ }^{4-12}$ Other reports have described a similar relationship to treatment with penicillamine. ${ }^{13-16}$ We report a further 7 patients who developed DILD during treatment with gold or penicillamine. In all cases there was an unequivocal temporal relationship between the development of DILD and treatment with these drugs. To identify the nature and extent of this clinical problem we have reviewed all the cases where this adverse reaction had been described.

\section{Case reports}

\section{CASE 1}

A woman, aged 49, developed RA in 1977. She had inflammatory arthritis involving the proximal interphalangeal (PIP), metacarpophalangeal (MCP), wrist, knee, and ankle joints. In June 1979 her haemoglobin was $10.4 \mathrm{~g} / \mathrm{dl}$, erythrocyte sedimentation rate (ESR) $79 \mathrm{~mm} / \mathrm{h}$, and Rose-Waaler titre 1:32. She had no nodules or extra-articular

Accepted for publication 19 June 1980

Correspondence to Dr D. L. Scott, Department of Investigative Pathology, Rheumatism Research Wing, Medical School, University of Birmingham, Birmingham, B15 2TJ. manifestations. A chest $x$-ray was normal, and she had no respiratory symptoms or signs. Gold was started.

After 6 intramuscular injections of $50 \mathrm{mg}$ sodium aurothiomalate she had an immediate postinjection reaction consisting of coldness and shivering. After 6 hours she developed a wheeze. Similar reactions occurred with the seventh and eighth injections, and she became increasingly dyspnoeic on exercise. Gold was discontinued. The severity of the dyspnoea increased over the next month, and she was found to have fine crepitation in both lung fields. A chest $x$-ray showed diffuse interstitial shadowing (Fig. 1). Respiratory function tests indicated a restrictive defect, and the vital capacity was $2 \cdot 04$ 1. (1.89 standard deviations below the predicted value). The transfer factor for carbon monoxide was $3.6 \mathrm{mmol} /$ $\mathrm{min} / \mathrm{kPa} \quad(3 \cdot 20$ standard deviations below the predicted value). An eosinophil count was $450 \times$ $10^{6} / 1$. Immunoglobulin estimation showed a raised $\mathrm{IgA}$ at $9.0 \mathrm{~g} / 1$ (reference range $0.8-4.5 \mathrm{~g} / \mathrm{l}$ ) with normal IgG and IgM levels. C3 and C4 complement levels were normal. A platelet aggregation test for soluble immune complexes was negative. A serum gold level was $1.55 \mathrm{mg} / 16$ weeks after the last injection.

She received no specific therapy and improved gradually over the next 2 months. The radiological changes regressed. Lung function tests returned towards normal (vital capacity 2.661 ; transfer factor for carbon monoxide $4.6 \mathrm{mmol} / \mathrm{min} / \mathrm{kPa}$ ). She had no respiratory symptoms. 


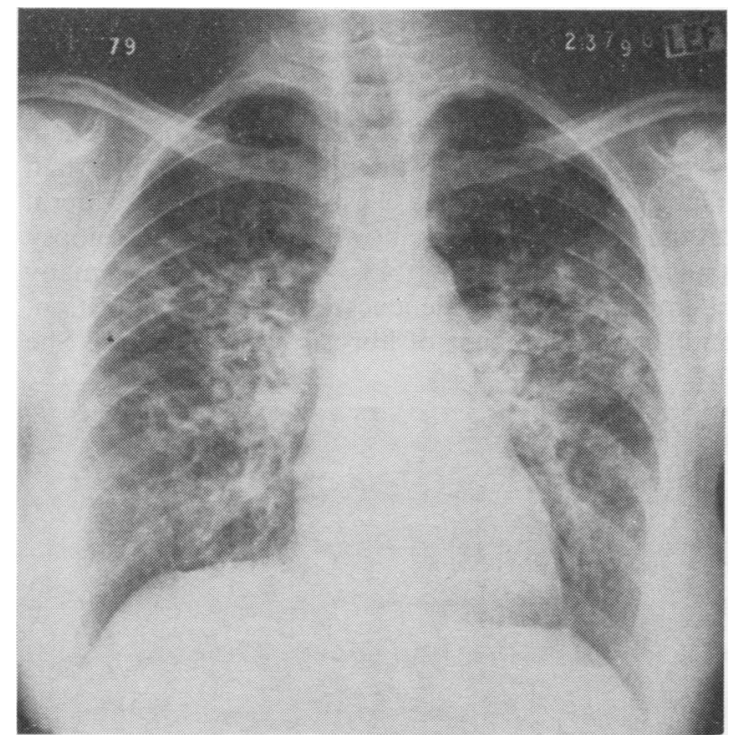

Fig. 1 Chest radiograph of case 1, aged 49, with RA, 1 month after the onset of DILD due to gold. There is bilateral diffuse interstitial shadowing.

CASE 2

A woman aged 55 years developed acute RA involving her hands, wrists, elbows, shoulders, and knees in 1979. Her haemoglobin was $11.5 \mathrm{~g} / \mathrm{dl}$, ESR 118 $\mathrm{mm} / \mathrm{h}$, and Rose-Waaler titre 1:64. There were no extra-articular lesions. She had no signs or symptoms of chest disease, and her chest $x$-ray was normal. She was started on weekly intramuscular injections of $50 \mathrm{mg}$ sodium aurothiomalate and $1 \mathrm{mg}$ Synacthen depot (tetracosactrin in zinc complex).

After 7 injections of gold she suddenly developed severe breathlessness, with crepitations in the left lung. A chest $x$-ray showed bilateral interstitial shadowing. She was hypoxic and the $\mathrm{Po}_{2}$ was 6.8 $\mathrm{kPa}$ and $\mathrm{PCO}_{2} 5.0 \mathrm{kPa}$. A serum gold level 8 days after the last injection was $3.6 \mathrm{mg} / \mathrm{l}$. She had an IgE response to a last dose of $5 \mathrm{mg}$ sodium aurothiomalate: the predose IgE level was $80 \mathrm{U} / \mathrm{ml}$ and 24 hours after the injection it was $5000 \mathrm{U} / \mathrm{ml}$ (normal range 1-375 $\mathrm{U} / \mathrm{ml}$ ). No further injections of gold were given, and over the next 6 months she showed a gradual improvement in her symptoms, though neither her symptoms or radiographic changes had completely resolved.

\section{CASE 3}

A man aged 56 developed over 4 months in 1977 a severe symmetrical polyarthritis involving most joints, and he felt unwell. There were no subcutaneous nodules or other extra-articular manifestations of RA. He had no respiratory symptoms or signs, and a chest radiograph was normal. His haemoglobin was $14.6 \mathrm{~g} / \mathrm{dl}$, ESR $18 \mathrm{~mm} / \mathrm{h}$, and the latex test was positive but a Rose-Waaler test negative. He was started on gold and received $50 \mathrm{mg}$ sodium aurothiomalate weekly by intramuscular injections. After 4 months he developed proteinuria and the gold was stopped. One month later he had marked exertional dyspnoea, with widespread rhonchi and crepitations. A chest radiograph showed diffuse interstitial shadowing. Over the next 4 weeks his respiratory symptoms and signs rapidly improved. An $x$-ray 2 years later was normal. Gold therapy was associated with eosinophilia: before treatment the eosinophil count was $180 \times 10^{6} / 1$; after 3 months of gold it was $984 \times 10^{6} / 1 ; 2$ months after stopping gold it was $360 \times 10^{6} / 1$.

\section{CASE 4}

A man developed RA in 1965 aged 53 years. It progressed and by 1969 involved the MCP, wrist, shoulder, knee, ankle, and metatarsophalangeal joints. There were no nodules or other extraarticular lesions. He had no respiratory symptoms, and a chest $x$-ray was normal. His haemoglobin was $10.4 \mathrm{~g} / \mathrm{dl}$, ESR $88 \mathrm{~mm} / \mathrm{h}$, and Rose-Waaler titre $1: 256$. Between 1969 and 1972 he was given 2 courses of gold. Both were stopped after 13 and 14 intramuscular injections respectively of $50 \mathrm{mg}$ sodium aurothiomalate owing to the development of proteinuria. In 1972 during the second course of gold he suddenly developed exertional dyspnoea and fine crepitations in the left lung. A chest $x$-ray showed bilateral diffuse interstitial shadowing. His breathlessness lasted several months. However, by 1973, 6 months after finishing gold, he had no chest symptoms or signs, and a chest $x$-ray was normal.

\section{CASE 5}

A man developed psoriatic arthritis in 1964 aged 53 years. It involved his distal interphalangeal, elbow, and knee joints. His haemoglobin was $12.0 \mathrm{~g} / \mathrm{dl}$ and ESR $57 \mathrm{~mm} / \mathrm{h}$. Latex and Rose-Waaler tests were negative. He had no symptoms or signs of chest disease, though a chest $x$-ray showed bilateral apical fibrosis. No cause was found for this despite thorough investigation. Repeated tests of his sputum for tuberculosis were negative. In 1970 his arthritis was worse, and prednisolone (20 $\mathrm{mg}$ daily) was started. He remained on steroids for the next 6 years.

In 1971 he was started on weekly intramuscular injections of $50 \mathrm{mg}$ sodium aurothiomalate. He had no chest symptoms or signs and his chest $x$-ray was unchanged. After 12 injections he developed a skin rash. After 4 weeks gold was recommenced. He then 
suddenly developed exertional dyspnoea. This progressed, and after 20 injections of gold he was breathless on minimal exertion. He had bilateral crepitations and rhonci. A chest $x$-ray showed widespread interstitial shadowing in both lower zones in addition to the apical changes. He developed proteinuria, and gold was stopped. A single further gold injection 6 months later caused severe thrombocytopenia.

Over the next 6 years he continued to have marked dyspnoea. His chest radiograph showed diffuse fibrosis (Fig. 2). Lung function tests showed a restrictive defect with a reduced vital capacity of 2.04 1 (2.90 standard deviations below predicted value) and a reduced transfer factor of $2.0 \mathrm{mmol} / \mathrm{min} /$ $\mathrm{kPa}(2.92$ standard deviation below the predicted value).

CASE 6

A woman presented in 1976 aged 50 years. She had an 8-year history of RA involving PIP, MCP, wrist, and MTP joints. There were subcutaneous nodules but no other extra-articular features. Her haemoglobin was $10.5 \mathrm{~g} / \mathrm{dl}$, ESR $38 \mathrm{~mm} / \mathrm{h}$, and RoseWaaler titre $1: 64$. She had no symptoms or signs of respiratory disease, and her chest $x$-ray was normal. An eosinophil count was $405 \times 10^{6} / 1$.

Gold was started. After 7 intramuscular injections of $50 \mathrm{mg}$ sodium aurothiomalate she developed an

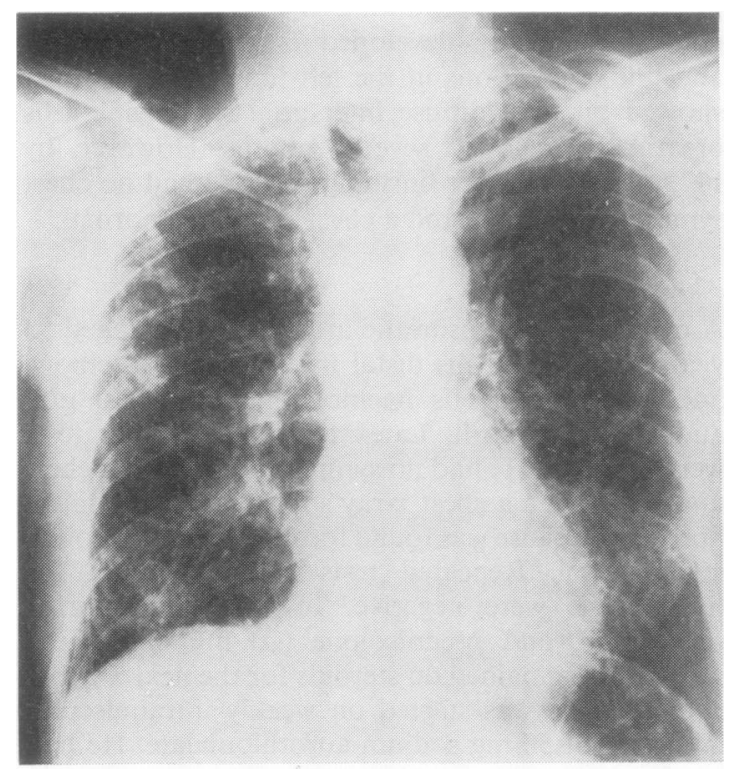

Fig. 2 Chest radiograph of case 5, aged 64, with psoriatic arthritis, 8 years after the onset of DILD due to gold. There are changes of diffuse pulmonary fibrosis. eosinophilia; the eosinophil count was $1170 \times 10^{6} / 1$. Further injections of gold were not given, but that same week she developed dyspnoea, and over the next 4 weeks the exertional dyspnoea increased in severity until she was breathless at rest. She had bilaterial crepitations. A chest $x$-ray showed bilateral diffuse interstitial shadowing. A lung biopsy showed an inflammatory infiltrate with many polymorphonuclear leucocytes, fibrin deposition, and the development of fibrosis (Figs 3 and 4). She

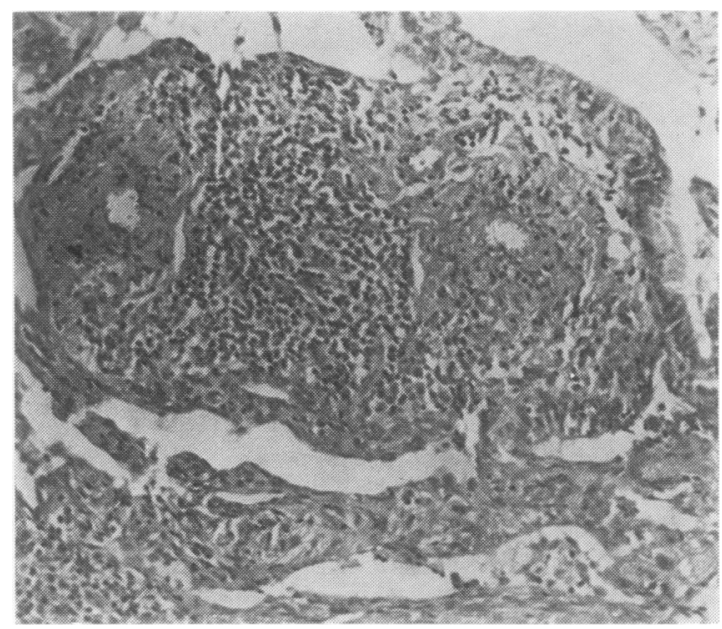

Fig. 3 Lung biopsy from case 6, aged 51, with $R A$. Tissues stained with haemotoxylin and eosin $(\times 482)$ showing polymorphonuclear, lymphocyte, and plasma cell infiltration and alveolar septal thickening.

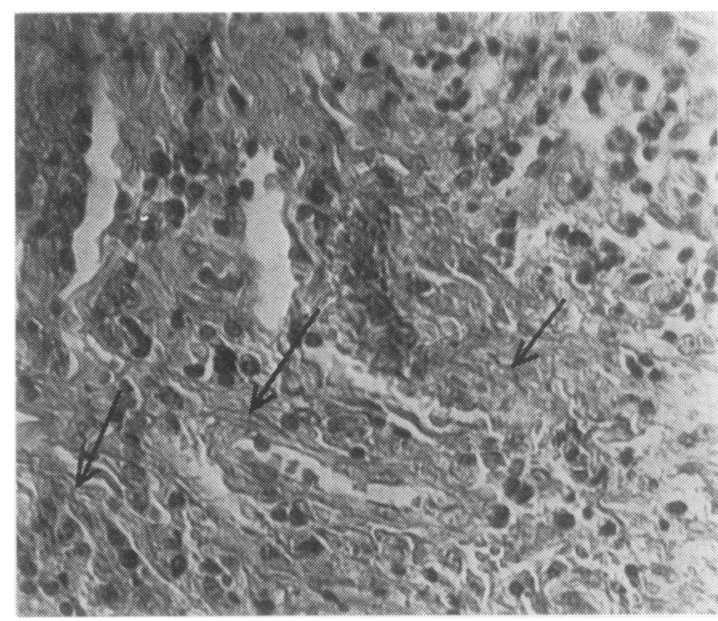

Fig. 4 Lung biopsy from case 6, aged 51, with $R A$. Tissues stained with Martius scarlet blue $(\times 482)$ showing the presence of collagen fibres (arrowed). These were blue in the original. 
was started on $10 \mathrm{mg}$ prednisolone daily. Lung function tests showed a restrictive defect with a reduced vital capacity of 1.831 (predicted value $3.84 \mathrm{l}$ ) and a reduced transfer factor of $7 \mathrm{ml} / \mathrm{min} /$ $\mathrm{mmHg}$ (predicted value $26 \mathrm{ml} / \mathrm{min} / \mathrm{mmHg}$ ).

Over the next 3 years there was evidence of some improvement. The vital capacity increased to 3.01 and the transfer factor increased to $8.5 \mathrm{ml} / \mathrm{min} /$ $\mathrm{mmHg}$. However, the chest radiograph remained abnormal and showed diffuse fibrotic changes.

CASE 7

A man developed RA in 1958 aged 33 years. Over the next 6 years he had progressive disease involving his shoulders, elbows, hands, knees and ankles, with rheumatoid nodules but no other extra-articular manifestations of RA. There was no evidence of pulmonary disease, and a chest $x$-ray was normal. In 1964 his haemoglobin was $13.0 \mathrm{~g} / \mathrm{dl}$, ESR 70 $\mathrm{mm} / \mathrm{h}$, and Rose-Waaler titre $1: 4096$. He was given 2 courses of gold with little effect and in 1964 was started on steroids; he had 5-10 mg prednisolone daily until 1977.

In 1974 he was started on penicillamine, and the dose was gradually increased to $1 \mathrm{~g}$ daily. At this time he had a normal chest $x$-ray and no evidence of respiratory disease. An eosinophil count before receiving penicillamine was $128 \times 10^{6} / 1$.

After 19 months' treatment with penicillamine he developed exertional dypsnoea of rapid onset. At this time his chest $x$-ray was normal. His dyspnoea continued, and after 24 months of penicillamine therapy he had bilateral basal crepitations and an abnormal chest $x$-ray; this showed the changes of diffuse intersititial pulmonary fibrosis in the mid and lower zones. Respiratory function tests showed a restrictive defect; the vital capacity was 3.451 (normal range $3 \cdot 43-5 \cdot 75$ ) and the transfer factor $3 \cdot 7 \mathrm{mmol} / \mathrm{min} / \mathrm{kPa}$ (normal range 6.8-13.6). Penicillamine was stopped after 26 months. An eosinophil count at this time was $1000 \times 10^{6} / 1$. Over the next 2 years his pulmonary function did not change.

\section{Discussion}

The characteristic features of DILD associated with gold and penicillamine therapy are the sudden onset of dyspnoea, crepitations, and bilateral diffuse pulmonary shadowing. Finger clubbing is not a feature of these patients. Our 7 cases are similar to those previously reported. There are now (27) reported cases of DILD associated with gold and penicillamine therapy and these are summarised in Tables 1 and 2. No single case provides indisputable proof that the gold and penicillamine are the cause of the pulmonary disease. However, the evidence is convincing when all the cases are considered as a group. This adverse reaction is similar to that seen with drugs such as azathioprine, ${ }^{17}$ melphalan, ${ }^{18}$ and cyclophosphamaide. ${ }^{19}$ In our 7 cases it developed after cumulative doses of $350-1000 \mathrm{mg}$ sodium aurothiomalate and $500 \mathrm{~g}$ penicillamine.

There was considerable evidence in our patients of hypersensitivity to gold and penicillamine. Eosinophil counts during therapy were available in

Table 1 Diffuse interstitial lung disease due to gold

\begin{tabular}{|c|c|c|c|c|c|c|c|c|}
\hline Case & $\operatorname{Sex}$ & Age & Diagnosis & \multirow{2}{*}{$\begin{array}{l}\begin{array}{l}\text { Disease } \\
\text { duration } \\
\text { (years) }\end{array} \\
10\end{array}$} & $\begin{array}{l}\text { Rose- } \\
\text { Waaler }\end{array}$ & Steroids & Response & Source \\
\hline 1 & $\mathbf{F}$ & 54 & RA & & $+\mathbf{v e}$ & Given & Improved & Geddes, Brostoff 2 \\
\hline 2 & $\mathbf{F}$ & 45 & RA & 2 & - ve & Not given & Resolved & Winterbauer et al. 3 \\
\hline 3 & $\mathbf{M}$ & 71 & OA & 7 & NA & Given & Resolved & Winterbauer et al. ${ }^{3}$ \\
\hline 4 & $\mathbf{F}$ & 47 & $\mathbf{R A}$ & $1 \frac{1}{2}$ & NA & Given & Resolved & Gould et al.4 \\
\hline 5 & $\mathbf{M}$ & 48 & RA & 13 & NA & Given & Improved & Gould et al. 4 \\
\hline 6 & $\mathbf{F}$ & 63 & RA & 10 & NA & Not given & Died & Gould et al. 4 \\
\hline 7 & $\mathbf{F}$ & 41 & RA & 13 & $+\mathrm{ve}$ & Given & Improved & James et al.s \\
\hline 8 & $\mathbf{F}$ & 61 & RA & 2 & - ve & Given & Resolved & Scharf et al. 6 \\
\hline 9 & $\mathbf{F}$ & 67 & RA & 2 & $+\mathrm{ve}$ & Given & Resolved & Tala et al. 2 \\
\hline 10 & $\mathbf{F}$ & 39 & RA & $3 \frac{1}{2}$ & $+\mathrm{ve}$ & Given & Improved & Sepuya et al. 8 \\
\hline 11 & $\mathbf{M}$ & 62 & RA & 2 & +ve & Given & Improved & Weavers Law9 \\
\hline 12 & $\mathbf{F}$ & 57 & $\mathbf{R A}$ & 2 & - ve & Not given & Resolved & Limpisvasti, Jones 10 \\
\hline 13 & $\mathbf{F}$ & 74 & RA & 25 & - ve & Given & Improved & Podell et al.11 \\
\hline 14 & $\mathbf{F}$ & 66 & RA & $1 \frac{1}{2}$ & $+\mathbf{v e}$ & Given & Resolved & Smith, Ball12 \\
\hline 15 & $\mathbf{F}$ & 51 & $\mathbf{R A}$ & 2 & + ve & Not given & Improved & This report \\
\hline 16 & $\mathbf{F}$ & 55 & RA & 1 & + ve & Given & Improved & This report \\
\hline 17 & $\mathbf{M}$ & 58 & RA & 1 & - ve & Not given & Resolved & This report \\
\hline 18 & $\mathbf{M}$ & 60 & $\mathbf{R A}$ & 7 & $+\mathbf{v e}$ & Not given & Resolved & This report \\
\hline 19 & $\mathbf{M}$ & 61 & $\begin{array}{l}\text { Psoriatic } \\
\text { arthritis }\end{array}$ & 8 & $-\mathrm{ve}$ & Given & $\begin{array}{l}\text { No } \\
\text { improvement }\end{array}$ & This report \\
\hline 20 & $\mathbf{F}$ & 50 & RA & 8 & $+v e$ & Given & Improved & This report \\
\hline
\end{tabular}

NA $=$ Not available. 
Table 2 Diffuse interstitial lung disease due to penicillamine

\begin{tabular}{|c|c|c|c|c|c|c|c|c|}
\hline Case & Sex & Age & Diagnosis & $\begin{array}{l}\text { Disease } \\
\text { duration } \\
\text { (years) }\end{array}$ & $\begin{array}{l}\text { Rose- } \\
\text { Waaler }\end{array}$ & Steroids & Response & Source \\
\hline $1 *$ & $\mathbf{M}$ & 46 & $\begin{array}{l}\text { Wilson's } \\
\text { disease }\end{array}$ & 5 & - & Not given & Died & Sternlieb et al. ${ }^{13}$ \\
\hline $2 *$ & $\mathbf{F}$ & 18 & $\begin{array}{l}\text { Wilson's } \\
\text { disease }\end{array}$ & 9 & - & Not given & Died & Died \\
\hline $3 *$ & $\mathbf{F}$ & 30 & $\begin{array}{l}\text { Wilson's } \\
\text { disease }\end{array}$ & $4 \frac{1}{2}$ & & Given & Died & \\
\hline $\begin{array}{l}4 * \\
5 \\
6 \\
7\end{array}$ & $\begin{array}{l}\mathbf{M} \\
\mathbf{F} \\
\mathbf{F} \\
\mathbf{M}\end{array}$ & $\begin{array}{l}51 \\
49 \\
52 \\
50\end{array}$ & $\begin{array}{l}\text { RA } \\
\text { RA } \\
\text { RA } \\
\text { RA }\end{array}$ & $\begin{array}{r}6 \\
6 \\
4 \\
17\end{array}$ & $\begin{array}{l}+v e \\
+v e \\
+v e \\
+v e\end{array}$ & $\begin{array}{l}\text { Given } \\
\text { Not given } \\
\text { Given } \\
\text { Given }\end{array}$ & $\begin{array}{l}\text { Resolved } \\
\text { Improved } \\
\text { Resolved } \\
\text { No } \\
\text { improvement }\end{array}$ & $\begin{array}{l}\text { Gibson et al. }{ }^{14} \\
\text { Eastmond15 } \\
\text { Peterson, Moller } 16 \\
\text { This report }\end{array}$ \\
\hline
\end{tabular}

-Cases 1-4 had Goodpasture's syndrome with renal as well as pulmonary involvement.

3 cases and all were raised. This is a significant finding. ${ }^{20}$ One patient had an IgE response to gold and another had an immediate postinjection reaction. ${ }^{21}$ Finally 3 patients had proteinuria and 1 had thrombocytopenia and a rash.

DILD due to gold and penicillamine is not confined to RA. Winterbauer et $a .^{3}$ reported these $^{3}$ changes in a patient with osteoarthritis given gold, and Sternlieb et al..$^{13}$ have reported DILD as part of Goodpasture's syndrome in patients with Wilson's disease receiving penicillamine. One patient in our series had psoriatic arthritis and developed DILD when given gold. This patient had pulmonary disease before receiving gold with bilateral apical fibrosis. Upper lobe pulmonary fibrosis has been described in ankylosing spondylitis ${ }^{22}$ and in 1 case of psoriatic arthritis. ${ }^{23}$ These upper lobe changes are not related to DILD.

Brannan et al..$^{24}$ describe a sequence of progressive changes in patients with DILD and RA. Initial soft pulmonary infiltrates precede extensive diffuse fibrosis. The same sequence occurs in DILD seen in association with gold and penicillamine therapy. The initial change is probably an acute inflammatory alveolitis that may resolve completely or may progress to pulmonary fibrosis. The extent of these changes varies considerably. Of the 27 reported patients with DILD associated with gold or penicillamine therapy (Tables 1 and 2) 11 (41\%) resolved completely, $12(44 \%)$ had varying degrees of pulmonary fibrosis, and $4(15 \%)$ died. Three of the deaths were in patients with Wilson's disease who also had renal involvement.

Many authors have recommended using steroids in DILD due to gold or penicillamine, but there is little evidence that they are of benefit. Of the 27 described patients with this complication (Tables 1 and 2) 18 patients were given corticosteroids and $6(33 \%)$ showed resolution of the lung disease. The use of corticosteroids in these patients may not affect the outcome.
The aetiology of lung disease in RA is diverse. Pleural effusions and pulmonary nodules are undoubtedly extra-articular manifestations. Patients reported in other series of DILD in RA have received gold, ${ }^{25}$ and in these it may have contributed to the development of the pulmonary disease. The pathological evidence for a relationship between pleural disease and necrobiotic nodules and RA is undisputed, but in DILD the pathological relationship is less certain. ${ }^{26}$

We conclude that DILD as a serious adverse reaction to gold and penicillamine is commoner than generally realised. The incidence of this adverse reaction can be satisfactorily determined only by a prospective study, and we suggest this merits serious consideration, possibly on a multicentre basis. Dyspnoea developing during gold or penicillamine therapy requires careful evaluation, and if there is any suggestion of DILD these drugs should be stopped, since some patients show evidence of regression of the lung changes with cessation of therapy.

We thank Professor K. W. Walton for helping us with the preparation of this paper.

\section{References}

1 Walker W C, Wright V. Pulmonary lesions and rheumatoid arthritis. Medicine (Baltimore) 1968; 47: 501-20.

2 Geddes D M, Brostoff F. Pulmonary fibrosis associated with hypersensitivity to gold salts. $\mathrm{Br}$ Med $J$ 1976; ii: 1444.

3 Winterbauer $\mathbf{R} \mathbf{H}$, Wilske $\mathbf{K} \mathbf{R}$, Wheelis $\mathbf{R} \mathbf{F}$. Diffuse pulmonary injury associated with gold treatment. $N$ Engl $J$ Med 1976; 294: 919-21.

- Gould P W, McCormack P L, Palmer D G. Pulmonary damage associated with sodium aurothiomalate therapy. $J$ Rheumatol 1977; 4: 252-60.

5 James D W, Whimster W F, Hamilton E B D. Gold lung. $\mathrm{Br}$ Med J 1978; ii: 1523-4.

- Scharf J, Nahir M, Klienhaus U, Barzilai D. Diffuse pulmonary injury associated with gold therapy. JAMA 1977; 237: 2411. 
7 Tala E, Javala S, Nurmela T, Vuori K. Pulmonary infiltrates associated with gold therapy. Scand $J$ Rheumatol 1979; 8: 97-100.

8 Sepuya S M, Grzybowski S, Burton J D, Clement J G. Diffuse lung changes associated with gold therapy. Can Med J 1978; 118: 816-8.

9 Weaver L T, Law J S. Lung changes after gold salts. Br J Dis Chest 1978; 72: 247-50.

10 Limpisvasti P, Jones P. Gold-associated pulmonary injury. Hawaii Med J 1979; 38: 43-5.

11 Podell T E, Klinenberg J R, Kramer L S, Brown R V. Pulmonary toxicity with gold therapy. Arthritis Rheum 1980; 23: 347-50.

12 Smith W, Ball G V. Lung injury due to gold treatment. Arthritis Rheum 1980; 23: 351-4.

13 Sternlieb I, Bennett B, Scheinberg I H. D-penicillamine induced Goodpasture's syndrome in Wilson's disease. Ann Intern Med 1975; 82: 673-6.

14 Gibson T, Burry H C, Ogg C. Goodpasture syndrome and D-penicillamine Ann Intern Med 1976; 84: 100.

15 Eastmond $\mathrm{C}$ J. Diffuse alveolitis as a complication of penicillamine treatment for rheumatoid arthritis. $\mathrm{Br} \mathrm{Med}$ $J$ 1976; i: 1506 .

16 Petersen J, Moller I. Miliary pulmonary infiltrates and penicillamine. Br J Radiol 1978; 51 : 915-6.

17 Rubin G, Baume P, Vandenberg R. Azathioprine and acute restrictive lung disease. Aust $N Z J$ Med 1972; 3: $272-4$.

18 Codling B W, Chakera T M H. Pulmonary fibrosis following therapy with melphalan for multiple myeloma. $J$ Clin Pathol 1972; 25: 668-73.

19 Kaplan R L, Waite D H. Progressive interstitial lung disease from prolonged methotrexate therapy. Arch Dermatol 1978; 114: 1800-2.

20 Davis P, Hughes G R V. Significance of eosinophilia during gold therapy. Arthritis Rheum 1974; 17: 964-8

21 Halla J T, Hardin J G, Linn J E. Post-injection nonvasomotor reactions during chrysotherapy. Arthritis Rheum 1977; 20: 1188-91.

22 Campbell A H, MacDonald C B. Upper lobe fibrosis associated with ankylosing spondylitis. $\mathrm{Br} \mathrm{J}$ Dis Chest 1965; 59: 90-101.

23 Guzman L R, Gall E P, Pitt M, Lull G. Psoriatic spondylitis: association with advanced non-granulomatous upper lobe pulmonary fibrosis. JAMA 1978 ; 239: 1416-7.

24 Brannan H M, Good A, Divertie M B, Baggenstoss A H. Pulmonary disease associated with rheumatoid arthritis. JAMA 1964; 189: 914-8.

25 Patterson C D, Harville W E, Pierce J A. Rheumatoid lung disease. Ann Intern Med 1965; 62: 685-97.

26 Talbot J A, Calkins E. Pulmonary involvement in rheumatoid arthritis. JAMA 1964; 189: 9113. 